\title{
Prevalência dos sintomas musculoesqueléticos em movimentadores de mercadorias com carga
}

\author{
Eduardo Concepción Batiz ${ }^{\mathrm{a}}$, Jandira lzabel da Silva Nunes, \\ Olga Elena Anzardo Licea ${ }^{\mathrm{c}}$ \\ a*eduardo.batiz@sociesc.org.br, IST/SOCIESC, Brasil \\ bnunesjan@hotmail.com, UNIPAR, Brasil \\ 'oanzardo@yahoo.com.br, UBS Comasa, Brasil
}

\begin{abstract}
Resumo
A atividade do trabalhador que manuseia cargas o predispõe a riscos decorrentes dos fatores biomecânicos, excesso de força, posturas inadequadas e dos fatores organizacionais que, quando utilizados de forma inadequada, sua aplicação repercute na saúde dos trabalhadores e na produção. 0 presente trabalho foi realizado em 3 comércios atacadistas e tem como objetivo identificar os fatores de risco que podem provocar a prevalência dos sintomas musculoesqueléticos. Aplicaram-se à amostra selecionada de 134 trabalhadores um questionário organizacional, questionário nórdico de sintomas osteomusculares e o guia para avaliação e prevenção dos riscos relativos à manipulação manual de cargas. Ressalta-se que pela carga que carregam, pelas posturas que adotam e pelos sintomas de dor (63,4\% da amostra) associados aos fatores anteriores, a atividade se constitui em um risco para a saúde. Os resultados corroboram com os estudos, estabelecendo fortes indícios entre a carga física do trabalho e os sintomas musculoesqueléticos.
\end{abstract}

Palavras-chave

Sintomas musculoesqueléticos. Carga física. Ergonomia.

\section{Introdução}

Com a industrialização acelerada, somada às necessidades econômicas imediatas das empresas instaladas, são geradas agressões constantes deixando, muitas vezes, os trabalhadores à mercê da sorte no que se refere à segurança e à saúde ocupacional. Tal situação não ocorre somente por falta de legislação ou equipamentos de segurança adequados, mas pela falta de conscientização sobre o aspecto de prevenção de perdas, principalmente nos acidentes e nas doenças ocupacionais. Diante desse quadro, as doenças ocupacionais que acometem tanto os membros superiores como a coluna vertebral dos trabalhadores constituem-se numa das causas mais comuns dos sintomas musculoesqueléticos relacionados ao trabalho.

0 trabalho tem uma acepção bastante ampla, abrangendo não apenas as máquinas e equipamentos utilizados para transformar os materiais, mas também toda situação em que ocorre o relacionamento entre o homem e seu trabalho. lsso envolve não somente o ambiente físico, mas também os aspectos organizacionais de como este trabalho é programado e controlado para produzir os resultados desejados. Assim, é importante a análise real da situação de trabalho o entendimento e compreensão das queixas dos trabalhadores, contextualizando-as em seu ambiente laborativo.

Na atividade laboral, pode não estar presente a relação adequada entre trabalho e saúde pela presença de riscos. Entre eles, podem ser destacados os esforços repetitivos, trabalho estático, esforço físico intenso, ritmos intensos de trabalho e posturas inadequadas. Quando as condições de trabalho não são adequadas, podem se converter em causas para o aparecimento ou agravamento de lesões, principalmente do sistema musculoesquelético.

No trabalho ou na vida cotidiana, a postura e o movimento são determinados pela atividade laboral exercida e pelo posto de trabalho. Ao adotar uma postura ou realizar um movimento, são acionados 
diversos músculos, ligamentos e articulações do corpo, que, quando trabalham em desarmonia, podem provocar danos à saúde do trabalhador. Com relação à carga física, os trabalhadores envolvem, para a realização das atividades, os membros superiores, inferiores e a coluna vertebral principalmente, que, devido às posturas inadequadas e à sobrecarga, estão sujeitos a lesões do sistema musculoesquelético. Por tais motivos é importante analisar os valores limites e, principalmente, as recomendações, como medidas eficazes para diminuir os riscos durante a manipulação de cargas.

0 excesso de carga de trabalho pode favorecer ou agravar os sintomas musculoesqueléticos, mais ainda em atividades altamente repetitivas e de sobrecarga dos membros superiores e da coluna vertebral. A distribuição de tarefas e a frequência do manuseio são elementos que devem ser considerados dentre os fatores organizacionais. Outras variáveis devem ser consideradas para a realização das tarefas que exigem manipulação de cargas e posturas inadequadas, como a frequência com que são realizadas ao longo da jornada de trabalho, o estado de fadiga do trabalhador, o formato e a disposição física da carga a ser manipulada.

Os sintomas musculoesqueléticos consistem em qualquer anormalidade temporária ou permanente do sistema musculoesquelético, resultando em dor ou desconforto. Pesquisadores australianos descrevem a "síndrome do uso em excesso" como sendo um distúrbio musculoesquelético caracterizado por dor, sensibilidade e, geralmente, perda funcional do grupo muscular e ligamentos submetidos a peso ou uso contínuos.

Os fatores de riscos dos sintomas musculoesqueléticos são multifatoriais, todavia, neste estudo, dá-se ênfase aos fatores biomecânicos que estão relacionados à postura, à força, e à repetitividade (COUTO; NICOLETTI; LECH, 1998; MALCHAIRE; 1998; GRANDJEAN; 1998; GRIECO; 1998). Quanto mais elevado o risco da demanda da hipovascularização, da hipoxia e da acumulação de fadiga, maiores serão os distúrbios. Sendo assim, os elementos mais acometidos são os tendões, nervos, cápsulas e os músculos que são susceptíveis aos sintomas, porque sua capacidade de recuperação é mais limitada.

Estudos realizados por vários especialistas apontam que os fatores de risco, para o desenvolvimento dos sintomas musculoesqueléticos associados ao empurrar e puxar, têm sido revisados em quatro perspectivas: epidemiológica, psicofísicas, fisiológicas e biomecânicas (MIEZEJEWSKI; KUMAR, 1997; HOOZEMANS et al., 1998).
Um grande número de estudos epidemiológicos apresenta prevalência de sintomas musculoesqueléticos relacionados às atividades que requerem movimentos repetitivos e o uso de força elevada de membros superiores (GRIECO; 1998; WATKINS, 1999).

Toda postura que force o corpo a sair da posição vertical de equilíbrio ocasiona fadiga muscular, caso seja constante. Entende-se que, todo trabalho executado com os membros superiores constantemente acima do nível dos ombros, é fatigante, independente da sustentação de carga. A fadiga será tanto mais intensa quanto mais pesada for a carga a ser sustentada. Assim, o uso das mãos fazendo força permanentemente para firmar um objeto, acarreta os efeitos da contração estática, podendo aparecer dor muscular, principalmente no polegar e indicador.

0 estágio inicial de distúrbios musculoesqueléticos está relacionado às queixas de cansaço ao final da fornada de trabalho, algo como uma fadiga muscular com duração de poucas horas. Já no estágio dois, além da fadiga, há também as dores, com mais intensidade, e cansaço que se estende por um período mais longo (FERREIRA JUNIOR, 2002). Para o autor, a fadiga ocorre quando o trabalho muscular é realizado durante um tempo prolongado, podendo ocasionar a realização menos cuidadosa ou precisa da atividade, que pode resultar em acidentes ou em movimentos inadequados, provocando lesões.

A Organização Internacional do Trabalho (OIT) afirma que a manipulação manual de cargas é uma das causas mais frequentes de acidentes laborais, com 20 a $25 \%$ do total dos acidentes ocorridos (ESPAÑA, 2003).

Nos países industrializados, perto de um terço dos dias laborais perdidos, relacionados a problemas de saúde, se devem a transtornos musculoesqueléticos. Destes dias, 60\% se relacionam com problemas localizados nas costas (CHILE, 2008).

Esta problemática também está presente em muitos países da União Europeia (UE). A dor nas costas afeta $23,8 \%$ dos trabalhadores. Os dados da IV enquete Europeia sobre condições de trabalho acusam que $34,4 \%$ dos trabalhadores transportam ou deslocam cargas pesadas. 0 custo econômico para a EU oscila entre 2,6e 3,8\% do Produto Nacional Bruto (CHILE, 2008).

No Reino Unido, um relatório realizado em 1991 mostra que a causa de 34\% dos acidentes causadores de lesões foi a manipulação de cargas. Destes acidentes, 45\% se localizaram nas costas. $\mathrm{Na}$ França, durante o ano 1992, a manipulação de carga foi a causa de 31\% dos acidentes de trabalho com afastamento. Na Espanha, a maior causa de acidentes de trabalho no período 1994-1995 foi 
devido à sobrecarga; as estatísticas de acidentes de trabalho e doenças profissionais de 1996 mostram que $22,2 \%$ de acidentes de trabalho com afastamento foram causados por sobrecarga, muitos deles devido provavelmente à movimentação manual de cargas; e quanto à natureza da lesão, $8,9 \%$ dos acidentes foi devido a lombalgias e $0,1 \%$ a hérnias de disco (ESPAÑA, 2003).

Nos Estados Unidos, um estudo realizado em 1990 pelo National Safety Council, põe em evidência que a maior causa de lesões laborais, equivalentes a 31\%, refere-se à sobrecarga (ESPAÑA, 2003). A mesma fonte destaca que as costas são a parte do corpo mais frequentemente lesionada ( $22 \%$ de 1,7 milhão de lesões).

Os transtornos musculoesqueléticos nos Estados Unidos, segundo estudos realizados no ano 2001 pelo Bureau of Labor Statistics, representam a maior parte componente dos custos devido a lesões relacionadas ao trabalho. Nesse estudo, se ressalta que $42 \%$ dos dias perdidos por estas lesões se associam com trabalhos de movimentação manual de cargas (WATERS, 2004).

No Chile, por exemplo, os organismos administradores do Seguro contra Acidentes do Trabalho e Doenças Profissionais mostram em suas estatísticas que a síndrome de dor lombar devido à sobrecarga física representa o terceiro lugar de dias totais de tratamento ou número de casos (CHILE, 2008).

0 levantamento manual de cargas é uma das maiores causas de dores nas costas, uma vez que muitos trabalhos envolvem levantamento de pesos que não satisfazem os requisitos ergonômicos (GOMEZ; AMILLO, 1997).

No ano de 2006, houve, em Navarra, Espanha, 4.122 acidentes de trabalho por sobrecarga, o que representou 32,4\% dos acidentes notificados, porcentagem que está se incrementando nos últimos anos; sendo notificadas 291 recaídas por esse motivo. Da mesma forma, foram relatadas 1.417 doenças profissionais musculoesqueléticas que representam 93,2\% das doenças profissionais notificadas, existindo 419 recaídas. Por outro lado, no ano de 2002, em Navarra, perderam-se 41.004 jornadas de trabalho por doenças profissionais musculoesqueléticas com uma duração média de afastamento de 24,76 dias de trabalho. Contemplando o total de transtornos musculoesqueléticos durante o ano de $2002 \mathrm{em}$ Navarra, se perderam mais de 114.713 jornadas de trabalho (INSTITUTO..., 2008).

Este estudo teve como objetivo identificar os fatores de risco que podem provocar a prevalência dos sintomas musculoesqueléticos associados ao manuseio e transporte de cargas dos movimentadores de mercadorias.

\section{Material e métodos}

A população estudada foi a de movimentadores de cargas de comércios atacadistas devido ao volume e peso que carregam e às queixas de dores que os trabalhadores manifestam e que, segundo eles, são ocasionadas pela atividade. Foram estudados 3 comércios atacadistas da região sul do Brasil, escolhidos de forma intencional devido às características das atividades e por serem representativos das manifestações de queixas antes mencionadas. A quantidade de trabalhadores na atividade de movimentação de cargas que compõem a população estudada é de cento e cinquenta e dois.

A amostra selecionada foi intencional, dela participando um total de cento e trinta e quatro trabalhadores; o que representa 88,1\% do total. Com o objetivo de que a amostra fosse representativa da população estudada, foi definido trabalhar com um nível de confiança de 95\%, e foi selecionada a seguinte amostra, de cada comércio atacadista estudado, apresentada na Tabela 1.

Destaca-se que, com a amostra selecionada de cada comércio atacadista, se garante um erro amostral de 5\%, o que faz que seja confiável e que seus resultados possam ser considerados para toda a população. Quando se analisa a base do total geral dos 3 comércios atacadistas, se observa que, para garantir o mesmo erro amostral, só se precisaria de uma amostra de 111 trabalhadores, 23 a menos da quantidade total, quando analisada separadamente. Os autores decidiram então, manter a amostra individual que garante um erro amostral de 5\% para cada comércio atacadista, para que a informação seja confiável para cada um deles individualmente; portanto a amostra final estudada foi de 134 movimentadores de cargas.

Com relação à caracterização da amostra, se observa que 100\% são do sexo masculino. A situação com relação à faixa etária da amostra se apresenta na Figura 1.

Na Figura 1, se observa que 93,3\% da amostra está com idade acima dos 30 anos, situação que demonstra estreita relação na amostra analisada referente aos anos de trabalho neste tipo de atividade.

Tabela 1. Distribuição da amostra por comércio atacadista estudado.

\begin{tabular}{cccc}
\hline $\begin{array}{c}\text { Comércio } \\
\text { atacadista }\end{array}$ & $\begin{array}{c}\text { População } \\
\text { movimentadores carga }\end{array}$ & $\begin{array}{c}\text { Amostra } \\
\text { estudada }\end{array}$ & $\%$ \\
\hline 1 & 44 & 39 & 88,6 \\
2 & 71 & 61 & 85,9 \\
3 & 37 & 34 & 94,6 \\
Total & 152 & 134 & $\mathbf{8 8 , 1}$ \\
\hline
\end{tabular}




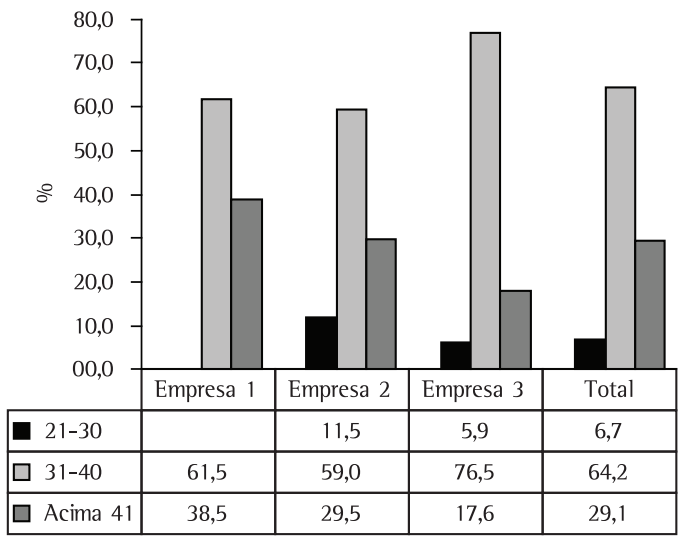

Figura 1. Distribuição da amostra por faixa etária

Consultados quanto ao tempo de serviço nesta atividade (Figura 2), constatou-se que a maioria atua a mais de 11 anos $(66,4 \%)$, portanto, apresentam uma ampla experiência no desempenho de suas atividades, todavia, não estão isentos dos riscos musculoesqueléticos.

Em uma primeira etapa, os autores deste trabalho realizaram o processo de ambientação através da aplicação das técnicas da observação direta e da análise documental com o objetivo de conhecer a atividade que seria analisada.

Determinou-se que as atividades que são realizadas pelos carregadores de mercadorias com cargas são realizadas por um longo período de tempo, totalizando uma jornada de trabalho de 10 a 12 horas/dia, sendo estas conduzidas por excesso de peso e posturas inadequadas.

Para a coleta de dados, foi elaborado e aplicado um questionário organizacional dividido em quatro partes. A primeira parte consta dos dados gerais do trabalhador pesquisado. Uma segunda parte composta por um total de 12 perguntas tem como objetivo se aprofundar em aspectos ocupacionais e

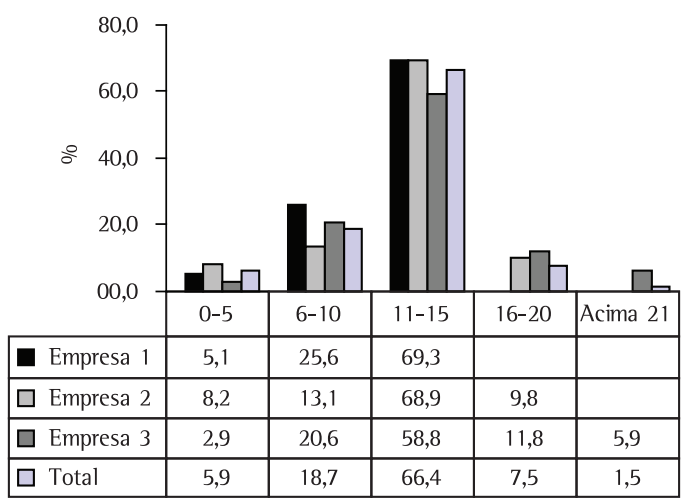

Figura 2. Distribuição da amostra por tempo de serviço na atividade analisada. organizacionais. São perguntas em que o pesquisado deveria escolher uma opção ou mais, segundo seja o caso. Em uma terceira parte do questionário, foram elaboradas 10 perguntas que têm como objetivo conhecer os sintomas de dor, desconforto, dormência ou falta de força da amostra. Por último, em uma quarta parte, foram formuladas 10 perguntas para conhecer sobre as condições ambientais em que são desenvolvidas as atividades dos pesquisados.

Numa etapa seguinte, realizou-se um teste-piloto com 10 trabalhadores voluntários para verificar a possibilidade de alguma modificação, análise da clareza e validade das perguntas do questionário. Depois da aplicação a uma amostra de 134 trabalhadores, pode-se verificar que o questionário atende aos interesses de qualquer outra pesquisa em que se analise a atividade de carregadores de cargas.

Uma das informações que o questionário organizacional forneceu se refere à porcentagem de dor na amostra analisada (Figura 3).

Os resultados mostram que 65,7\% da amostra apresenta dores em diferentes partes do corpo, portanto é necessário se aprofundar para conhecer em que momento se manifestam essas dores e quais as regiões do corpo mais afetadas.

Por isso, em uma segunda etapa da pesquisa e depois de analisados os resultados que o questionário organizacional ofereceu, optou-se pela aplicação do Questionário Nórdico de Sintomas Osteomusculares (QNSO) conhecido em inglês como Nordic Musculoskeletal Questionnaire (MNQ) (KUORINKA et al., 1987), que foi desenvolvido como uma proposta para padronizar a mensuração de relatos dos sintomas osteomusculares e poder dessa forma realizar comparações entre os estudos.

A escolha deste instrumento ocorreu pela necessidade de quantificar as regiões do corpo humano mais acometidas pelos sintomas osteomusculares, permitindo ao pesquisador poder aprofundar nas causas que provocam esses sintomas e propor as medidas mais adequadas para sua eliminação ou redução. Este questionário pode servir como um importante instrumento de diagnóstico do ambiente ou do posto de trabalho (BATIZ, 2001).

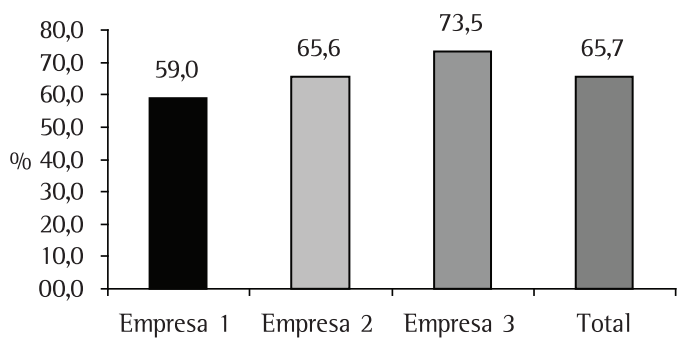

Figura 3. Porcentagem de sensação de dor na amostra analisada. 
Foi validado no Brasil utilizando uma amostra de noventa (90) caixas de uma instituição bancária estatal na cidade de Brasília. Os resultados mostraram concordância entre o relato de sintomas no NMQ e a história clínica em 86\% dos casos (PINHEIRO; TRÓCOLLI; CARVALHO, 2002).

Depois de analisados os resultados da aplicação do Questionário Nórdico de Sintomas Osteomusculares e conhecer as regiões do corpo em que se apresentam maiores sintomas de dor, foi aplicado o "Guia técnico para avaliação e prevenção dos riscos relativos à manipulação manual de cargas" (ESPAÑA, 1997).

Os motivos de sua aplicação foram devidos fundamentalmente ao fato de que era importante conhecer e avaliar, por um método cientificamente reconhecido, se as condições em que são realizadas as atividades e o peso que é carregado podem ser causas dos desconfortos que apresentam os trabalhadores.

Este guia é um método para reconhecimento dos riscos relativos à movimentação manual de cargas, conforme o Instituto Nacional de Seguridad e Higiene del Trabajo de Espanha, objetivando verificar se a atividade realizada pelos trabalhadores pode ser prejudicial à saúde.

Este guia permite identificar tarefas ou situações de trabalho com riscos dorsolombares não toleráveis. São classificadas como riscos não toleráveis cargas cujos pesos excedem a $3 \mathrm{~kg}$, e que se manipulam em condições ergonômicas desfavoráveis, ou seja, afastadas do corpo, com posturas inadequadas, com muita frequência, em condições ambientais desfavoráveis ou em solos irregulares. É importante destacar que, segundo o método, a carga que pesa mais de $25 \mathrm{~kg}$ constitui, por si só, um risco dorsolombar, mesmo em condições ergonômicas favoráveis.

0 guia técnico leva em consideração os seguintes indicadores:

Peso Aceitável = Peso teórico
$x$ Fator correção espaçamento vertical
$x$ Fator correção giro
$x$ Fator correção agarre
x Fator correção freqüência

O objetivo fundamental da aplicação do Guia Técnico espanhol era comprovar sua efetividade na análise de carregamento de cargas em trabalhadores como os contemplados na amostra analisada nas condições do Brasil. Este método já tinha sido utilizado para a avaliação da atividade de carregamento de pacientes em hospitais (BATIZ; VERGARA; LICEA, 2006), onde os resultados obtidos foram muitos bons.

\section{Resultados e discussão}

Uma informação que chamou a atenção dos autores deste artigo foi o fato de que $91,8 \%$ da amostra manifestou, através dos questionários, não haver recebido capacitação ou orientação para o exercício da atividade e só simplesmente palestras sem inclusão da prática. Esta situação é muitíssimo importante já que muitas das possíveis lesões musculoesqueléticas podem ser evitadas se os trabalhadores adotarem uma postura correta no momento da pega e carregamento da carga.

Difícil é estabelecer uma relação direta dos sintomas musculoesqueléticos com o tempo de trabalho e as condições de trabalho existentes, já que existem muitas variáveis que podem estar influindo em possíveis dores, como por exemplo, dores nas costas; mais ainda estabelecer uma relação entre dores e capacitação. Interessante é conhecer a relação tempo de trabalho, condições de trabalho e capacitação; este último como forma de adoção de posturas corretas e os possíveis sintomas musculoesqueléticos.

Poder-se-ia afirmar que, quando esses três fatores se encontram em proporções não desejadas, ou seja, na medida em que o tempo de trabalho é maior na atividade, as condições de trabalho são inadequadas e a capacitação é nula ou insuficiente, a probabilidade de aumentos de sintomas musculoesqueléticos são maiores.

Levando-se em consideração o tempo de serviço na atividade, com as observações que permitiram analisar as condições em que tais atividades são realizadas, pode-se inferir dos riscos aos quais estão expostos estes trabalhadores, haja vista que eles não possuem treinamento prévio nem avaliação do limite de sobrecarga física à qual se expõem no decorrer da jornada de trabalho. Portanto os sintomas musculoesqueléticos podem estar vinculados aos aspectos específicos de certos grupos de atividades exercidas e, com o passar dos anos, apesar de terem melhores conhecimentos nas suas profissões, precisam adaptar-se a um ritmo mais lento e mais adequado.

A todo o anterior se soma o fato de que 100\% dos trabalhadores manifestaram que não existem rodízios de tarefas e que as pausas, que impõem uma sobrecarga de trabalho, existindo só pausa de descanso para café da manhã, da tarde e horário de almoço, são insuficientes para se recuperar da atividade. 0 rodízio de tarefas é importante porque possibilita a diminuição na duração da exposição aos fatores de riscos impostos pela atividade exercida. Quando houver rodízios de tarefas, mas as outras tarefas apresentarem o mesmo padrão biomecânico, não haverá vantagem biomecânica de rodízio. 
No item relativo ao cansaço físico no final da jornada de trabalho, os dados obtidos através dos questionários evidenciam que 70,1\% (94 de 134) sentem-se cansados e 23,1\% (31 de 134) se sentem muito cansados. 0 cansaço relatado pela maioria destes trabalhadores está atrelado à grande sobrecarga física durante o desenvolvimento de suas atividades. Além disso, a sensação subjetiva de cansaço é o principal sintoma da fadiga que pode inibir as atividades ou até mesmo paralisá-las.

Os dados apresentados na Tabela 2 são relevantes à medida que estão associados à sobrecarga dinâmica e têm relação com a força e repetitividade dos movimentos. Nessa tabela, é apresentada a distribuição dos movimentos e posturas realizadas e identificadas como responsáveis pelo aumento da sintomatologia.

Observa-se na Tabela 2 que 93,3\% da amostra ergue ou manipula pesos com flexão do tronco. Similares resultados foram obtidos em uma pesquisa realizada com estivadores em um porto, em que, do total da frequência estimada de movimentos com flexão do tronco maior de $60^{\circ}, 100 \%$ apresentam compromisso biomecânico (GUZMÁN; POUTOU; CRUZ, 2005).
Vale frisar que a manutenção da postura em flexão do tronco, curvada para frente, aumenta excessivamente a pressão intradiscal exigindo grande esforço muscular de sustentação contra a ação da gravidade, e, ao se adotar esta postura diariamente, e por períodos prolongados, pode-se provocar um processo de dor lombar.

As sobrecargas por movimentos repetidos de torção ou rotação da coluna provocam distensões e rompimentos nas fibras do disco vertebral, favorecendo os processos de herniação. Nas situações rotineiras de levantamentos de peso, movimentos de torção, estiramentos ou traumatismos, podem ocorrer processos degenerativos nas estruturas articulares da coluna (CAILLIET, 2001).

Da mesma forma, se observa na Tabela 2 que $100 \%$ da amostra realiza movimentos acima dos ombros, o que pode trazer sérios comprometimentos osteomusculares. Se ao anterior se soma o fato de que toda a amostra manifestou que durante todo o tempo transportam mercadorias nos ombros mantendo posturas estáticas e que caminham por longos período de tempo (91,8\% da amostra), a situação fica mais grave, o que ajuda o surgimento de dores nas costas.

Tabela 2. Posturas e movimentos adotados frequentemente pelos movimentadores de mercadorias durante a jornada de trabalho.

\begin{tabular}{|c|c|c|c|c|}
\hline Itens & $\begin{array}{c}\text { Empresa } 1 \\
(\%)\end{array}$ & $\begin{array}{c}\text { Empresa } 2 \\
(\%)\end{array}$ & $\begin{array}{c}\text { Empresa } 3 \\
(\%)\end{array}$ & $\begin{array}{c}\text { Total } \\
(\%)\end{array}$ \\
\hline Carregar peso com menos de $23 \mathrm{~kg}$ & 100,0 & 100,0 & 100,0 & 100,0 \\
\hline Puxar ou empurrar pesos com mais de $23 \mathrm{~kg}$ & 100,0 & 100,0 & 100,0 & 100,0 \\
\hline Carregar pesos com mais de $23 \mathrm{~kg}$ & 100,0 & 100,0 & 100,0 & 100,0 \\
\hline Erguer pesos com a mercadoria distante do corpo & 92,3 & 88,5 & 88,2 & 89,5 \\
\hline Erguer ou manipular pesos com flexão do tronco & 92,3 & 93,4 & 94,1 & 93,3 \\
\hline Erguer pesos acima do peito & 97,4 & 100,0 & 97,0 & 98,5 \\
\hline Erguer pesos dificeis de segurar & 89,7 & 86,9 & 87,9 & 87,3 \\
\hline Erguer algo muito pesado com mais de $50 \mathrm{~kg}$ & 89,7 & 68,8 & 79,4 & 77,6 \\
\hline Ficar de pé por longo tempo & 92,3 & 98,4 & 100,0 & 97,0 \\
\hline Caminhar por longo tempo & 82,1 & 96,7 & 94,1 & 91,8 \\
\hline Curvar-se bruscamente com a coluna & 100,0 & 95,1 & 91,2 & 95,5 \\
\hline Virar-se bruscamente com a coluna & 87,2 & 88,5 & 87,9 & 87,3 \\
\hline Virar-se e curvar-se com a coluna & 89,7 & 88,5 & 87,9 & 88,1 \\
\hline Trabalhar com postura curvada e torcida por tempo prolongado & 84,6 & 90,2 & 82,4 & 86,6 \\
\hline Alcançar mercadorias com suas mãos e braços & 94,9 & 90,2 & 94,1 & 92,5 \\
\hline Movimentos por acima dos ombros & 100,0 & 100,0 & 100,0 & 100,0 \\
\hline Exercer forças com suas mãos ou braços & 92,3 & 100,0 & 97,0 & 97,0 \\
\hline Curvar os seus punhos & 87,2 & 91,8 & 82,4 & 88,1 \\
\hline Manter seus punhos curvados por longo tempo & 76,9 & 70,5 & 79,4 & 74,6 \\
\hline Manter seus punhos torcidos por longo tempo & 69,2 & 70,5 & 79,4 & 72,4 \\
\hline Trabalhar nas mesmas posturas & 84,6 & 91,8 & 82,4 & 87,3 \\
\hline Fazer sempre os mesmos movimentos com seu tronco & 76,9 & 82,0 & 82,4 & 80,6 \\
\hline Fazer sempre os mesmos movimentos com seus braços & 84,6 & 91,8 & 87,9 & 88,1 \\
\hline Fazer sempre os mesmos movimentos com seus punhos & 79,5 & 88,5 & 87,9 & 85,1 \\
\hline Fazer movimentos repetitivos e inesperados & 82,1 & 95,1 & 82,4 & 88,1 \\
\hline Dificuldades em exercer força suficiente devido a posturas desconfortáveis & 74,4 & 90,2 & 94,1 & 86,6 \\
\hline Agachar para pegar mercadorias (flexão dos membros inferiores) & 97,4 & 100,0 & 100,0 & 99,3 \\
\hline Subir escadas & 100,0 & 60,6 & 76,5 & 76,1 \\
\hline Transportar mercadorias nos ombros & 100,0 & 100,0 & 100,0 & 100,0 \\
\hline
\end{tabular}


Guzmán, Poutou e Cruz (2005) demonstraram que as altas frequências de ações físicas com compromisso biomecânico, o excesso de peso manipulado ou a carga postural estática por períodos de tempo prolongados, demonstraram, no caso dos estivadores, risco de padecer afecções nas costas.

Um dado importante a ser ressaltado é que, do total de 29 itens analisados nas três empresas, 100\% apresentam valores totais superiores a 70\%, indicador este que chama a atenção dos autores deste artigo, já que todos foram indicadores negativos.

Pela dinâmica do trabalho observada nas três empresas, acredita-se que as diferentes posturas e movimentos que a atividade obriga os movimentadores de mercadorias pertencentes à amostra analisada adotarem frequentemente podem romper com o equilíbrio musculoesquelético, gerando processos dolorosos devido à grande sobrecarga física.

A Figura 4 apresenta os resultados obtidos quando analisadas as três empresas de forma conjunta das regiões anatômicas mais acometidas.
Com referência à região anatômica mais acometida neste tipo de atividade, de acordo com os resultados obtidos, constata-se que o esforço físico com carga, atribuído como causa, possui dados significativos, visto que a maioria dos sujeitos pesquisados afirma sentir dor em algum local do corpo, tendo como maior predominância a coluna lombar.

$\mathrm{Na}$ coluna lombar, a percepção do sintoma da dor revela-se em $92,5 \%$ dos sujeitos pesquisados. Tais dados condizem com o estudo de Burdorf (1993), ao enfocar que o trabalho físico pesado mostra-se claramente relacionado com a dor nas costas.

Wisner (1994) relata que cerca de $80 \%$ das pessoas expostas por longo tempo a uma atividade têm ou tiveram um problema de dor relacionado com a coluna. Isso sucede porque os trabalhadores, de uma maneira geral, passaram a trabalhar em posições incorretas, levantando peso de modo inadequado ou produzindo torções no tronco durante o expediente de trabalho muitas horas por dia, por muitas semanas, meses e anos causando um desgaste maior na coluna.

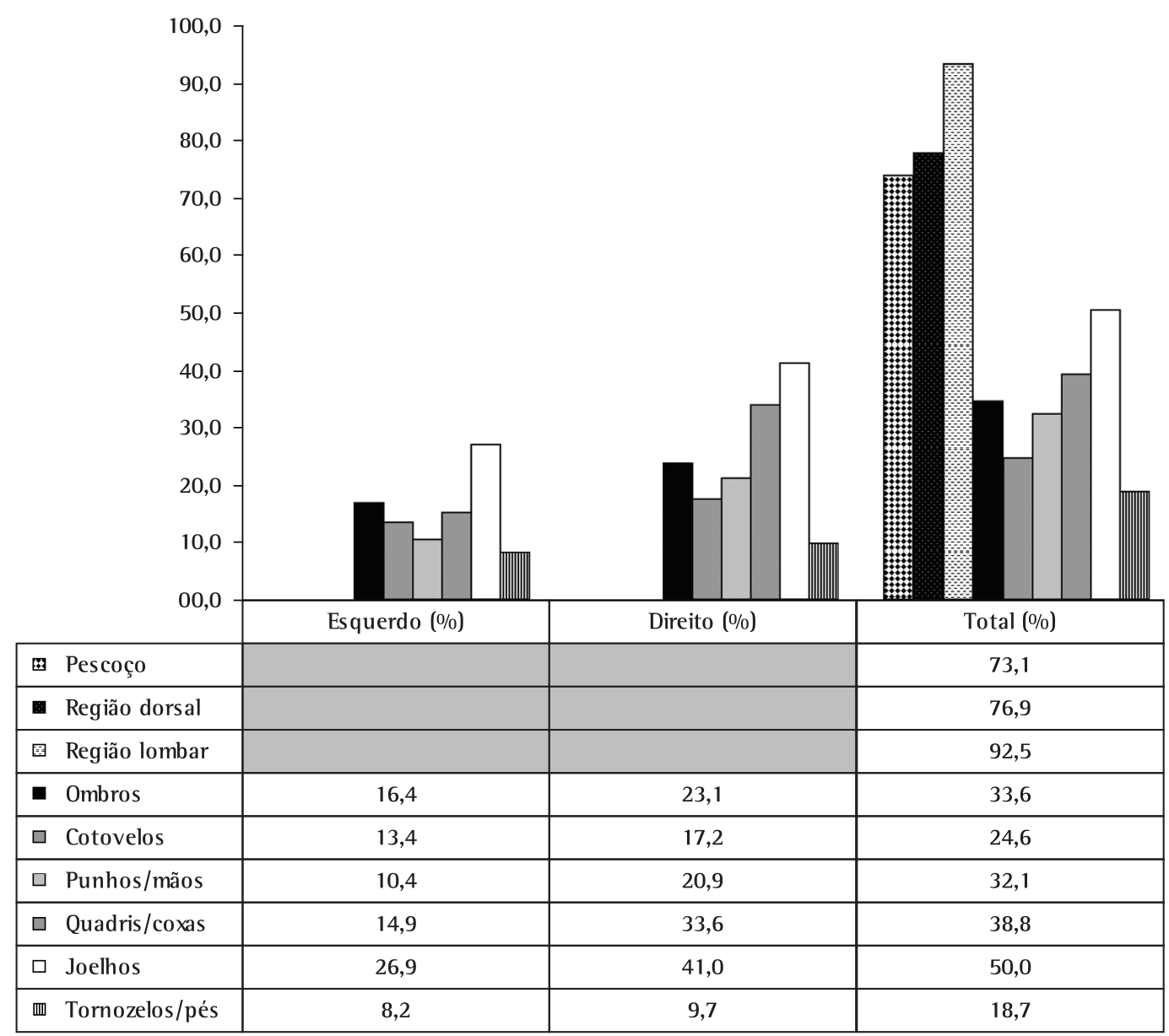

Figura 4. Regiões anatômicas com maior prevalência dos sintomas. 
As lesões na coluna, resultantes de levantamentos de pesos, são responsáveis por quase $12 \%$ de todas as lesões industriais e de 85 a $99 \%$ de todas as lesões graves na coluna, particularmente nos níveis de L4/L5 e L5/S1 (GONÇALVES, 1998).

Da Figura 4, destacam-se igualmente, como prevalência do sintoma dor a região dorsal, 76,9\%; o pescoço, 73,1\%; os joelhos, 50,0\%; quadris/coxas, 38,8\%; ombros, 33,6\%; punhos e mãos, 32,1\%; cotovelos, 24,6\%; e tornozelo/pé, 18,7\%.

A Figura 5 destaca os sintomas mais frequentes no final da jornada de trabalho, tendo a dor com $65,7 \%$, seguido pela fadiga e dor com $21,6 \%$, dor e cãibra com 17,2\% , desconforto com 14,2\%, e, finalmente, cãibra e fadiga com 14,9\%.

Este estudo mostra um percentual significativo de problemas relacionados à dor, o que também é confirmado por Miezejewski e Kumar (1997), Grandjean (1998), Hoozemans et al. (1998), Marras (2000), Vogt (2000) e Hildebrandt et al. (2001).

Conhece-se que os sintomas musculoesqueléticos e especialmente a dor lombar podem ser a expressão de muitas causas, existindo evidências que demonstram que sua natureza é multifatorial (BERNARD; 1997; KERR et al., 2001; CHILE, 2008).

Quando pesquisada a amostra para conhecer onde se concentrava a maior porcentagem de dores quando relacionado à porcentagem total encontrada nas três empresas e o tempo de trabalho na atividade, se observou que 53 dos 88 trabalhadores da amostra que apresentam dores, 60,2\% estão na atividade a mais de 10 anos.

Vogt (2000), ao referir-se aos indivíduos que trabalham mais de 10 anos numa mesma atividade, ressalta que estes relataram mais dor na região lombar do que os demais trabalhadores.

Vários fatores podem estar concorrendo para os elevados percentuais de dor entre os trabalhadores que manuseiam cargas. Estes dados podem estar atrelados a alguns aspectos observados com a idade, falta de tratamentos fisioterápicos, a inexistência de rodízios de tarefas, anos de serviço trabalhados, posturas e movimentos inadequados adotados frequentemente pelos movimentadores de mercadorias. Nesta mesma direção, é importante citar o estudo de Merino (1996) ao demonstrar a elevada incidência do sintoma musculoesquelético em trabalhadores com carga em relação às variáveis citadas.

Com o objetivo de conhecer se as condições em que são realizadas as atividades e o peso que é carregado podem ser causas dos desconfortos que apresentam os trabalhadores, foi aplicado o "Guia técnico para avaliação e prevenção dos riscos relativos à manipulação manual de cargas", e os resultados de sua aplicação se apresentam na Tabela 3.

Partindo do fato de que em todos os casos foi considerado um peso real da carga carregada pelos trabalhadores de $20 \mathrm{~kg}$ para poder comparar, se observa a diferença entre as três empresas e a causa

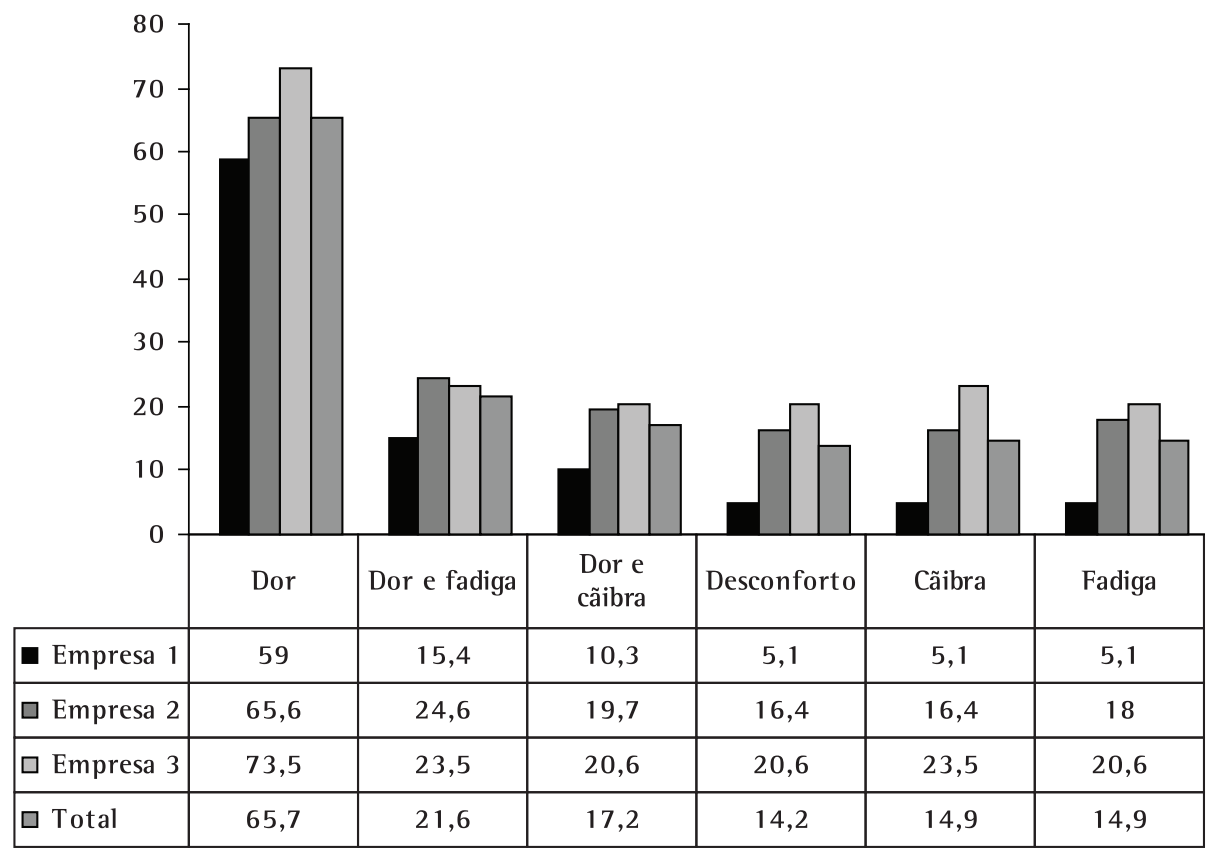

Figura 5. Distribuição dos sintomas mais frequentes. 
Tabela 3. Resultados da aplicação do método espanhol de carregamento de cargas manuais.

\begin{tabular}{|c|c|c|c|c|}
\hline \multirow[b]{2}{*}{ Empresa } & \multicolumn{4}{|c|}{ Tipo de atividades } \\
\hline & $\begin{array}{c}\text { Carregamento } \\
\text { caminhões }\end{array}$ & Descarregamento caminhões & Empilhamento cargas & Movimentação cargas \\
\hline Empresa 1 & $5,2-8,5 \mathrm{~kg}$ & $4,2-4,8 \mathrm{~kg}$ & $6,3-7,4 \mathrm{~kg}$ & $6,6-9,8 \mathrm{~kg}$ \\
\hline Empresa 2 & $4,3-7,1 \mathrm{~kg}$ & $3,8-4,4 \mathrm{~kg}$ & $7,1-7,3 \mathrm{~kg}$ & $7,5-9,6 \mathrm{~kg}$ \\
\hline Empresa 3 & $6,1-8,2 \mathrm{~kg}$ & $3,9-5,1 \mathrm{~kg}$ & $5,9-8,0 \mathrm{~kg}$ & $8,5-9,3 \mathrm{~kg}$ \\
\hline
\end{tabular}

fundamental se deve ao fato das condições em que são carregadas as cargas, a frequência de manipulação e as condições do agarre.

Nas três empresas, existe um fator comum e esse é que o peso aceitável que pode ser carregado nas condições analisadas está muito por baixo que o valor real e, por conseguinte, as atividades analisadas são inaceitáveis, podendo provocar sérios problemas à saúde dos trabalhadores.

Os trabalhadores manipulam cargas com pesos acima dos limites aceitáveis, além das pegas ruins, grandes frequências de manipulação, giros com o corpo, movimentos e posturas inadequadas que constituem riscos para a saúde.

Quando analisados os resultados obtidos na aplicação do questionário organizacional e analisados, neste artigo, os obtidos da aplicação do questionário Nórdico e os da aplicação do método espanhol de carregamento de cargas manuais, pode-se concluir que as atividades nas três empresas constituem riscos para a saúde, e que existe uma forte evidência de que os sintomas musculoesqueléticos apresentados na amostra estudada estão relacionados com as atividades analisadas.

\section{Considerações finais}

Observou-se que a atividade do trabalhador que manuseia cargas o predispõe a riscos decorrentes dos fatores biomecânicos, excesso de força, posturas inadequadas e dos fatores organizacionais que, quando utilizados de forma inadequada, sua aplicação repercute na saúde dos trabalhadores e na produção, dentre eles destacam-se as pausas insuficientes para o descanso, a falta de treinamentos e o piso inadequado para o desenvolvimento da atividade de manuseio e transporte de mercadorias que são pontos importantes e relevantes em qualquer avaliação da atividade de trabalho, dando origem a gênese dos sintomas musculoesqueléticos.

Os resultados encontrados apontam para a necessidade de melhorarias das condições de trabalho na atividade de movimentador de mercadorias com carga, assim como em outras atividades na qual o sacrifício e o esforço humano são uma constante.
Ressalta-se que pela carga (peso) que carregam, pelas posturas que adotam, pelos resultados do método espanhol e pelos sintomas de dor associados aos fatores anteriores, a atividade se constitui em um risco para a saúde.

Levando-se em consideração às associações encontradas entre as variáveis ocupacionais, espera-se que esta pesquisa possa servir de subsídios para o início de um trabalho preventivo junto aos trabalhadores que manuseiam cargas e para o desenvolvimento de futuras pesquisas.

\section{Referências}

BATIZ, E. C. Métodos de análise de posturas e carregamentos de cargas manuais. São Paulo: Centro Científico e Cultural Brasileiro de Fisioterapia - CBF, 2001. Apostila.

BATIZ, E. C.; VERGARA, L. G. L.; LICEA, O. E. A. Aplicação do método Reba para a análise das condições de trabalho de auxiliares de enfermagem no carregamento de pacientes. In: CONGRESSO BRASILEIRO DE ERGONOMIA - ABERGO, 2006, Curitiba. Anais... Curitiba, 2006.

BERNARD, B. P. Musculoskeletal Disorders and Workplace Factors. A Critical Review of Epidemiologic Evidence for Work-Related Musculoskeletal Disorders of the Neck, Upper Extremity, and Low Back. U.S. Department of Health and Human Services. Public Health Service Centers for Disease Control and Prevention. National Institute for Occupational Safety and Health, 1997. NIOSH Technical Report 97-141.

BURDORF, A. Bias in risc estimates from variability of exposure to postural load on the back in occupational groups. Scandinavian Journal of Work, Environment \& Health, v. 19, n. 1, p. 51-54, 1993. http://dx.doi. org/10.5271/sjweh. 1504

CAILlIET, R. Sindrome da dor lombar. 5. ed. Porto Alegre: Artmed, 2001. p. 138-150.

CHILE. Ministerio del Trabajo y Previsión Social. Subsecretaría de Previsión Social. Guía Técnica para la evaluación y control de los riesgos asociados al manejo o manipulación manual de carga. Chile, 2008.

COUTO, H. A.; NICOLETTI, S. J.; LECH, O. Como Gerenciar a Questão LER/DORT. Belo Horizonte: Ergo, 1998. p. 80-300-334-335.

ESPAÑA. Ministério de Trabajo y Asuntos Sociales - MTAS. Instituto Nacional de Seguridad e Higiene em el Trabajo - INSHT. Real Decreto 487/1997, de 14 de abril de 1997. Guía Técnica para la evaluación y prevención de los riesgos relativos a la Manipulación manual de cargas. Boletín Oficial del Estado, Madri, 23 abr. 1997. 
n. 97. Disponivel em: <http://www.insht.es/lnshtWeb/ Contenidos/Normativa/GuiasTecnicas/Ficheros/cargas. pdf>. Acesso: 14 fev. 2008.

ESPAÑA. Ministério de Trabajo y Asuntos Sociales - MTAS. Secretaria General de Acción Sindical. Real Decreto 487/1997 disposiciones mínimas de seguridad y salud relativas a la manipulación manual de cargas. Castilla y Leon: Comisiones Obreras - Unión Sindical de Castilla y León, 2003. Disponível em: <http://www. istas.ccoo.es/descargas/asesora/manipulacion $\% 20 \mathrm{de} \% 20$ cargas.pdf>. Acesso em: 25 jan. 2008.

FERREIRA JUNIOR, M. F. Saúde no Trabalho. São Paulo: Roca Ltda, 2002. p. 3-27.

GOMEZ, J.; AMILlO, H. Guia Técnica para la evaluación y prevención de los riesgos relativos a la Manipulación manual de cargas. Instituto Nacional de Seguridad e Higiene en el Trabajo, 1997. Disponível em: <http://www. ccoo.upv.es/salud-Laboral/Guia-manipulación-cargas/ G-cargas.htm>. Acesso em: 20 abr. 2001.

GONÇALVES, M. Variáveis biomecânicas analisadas durante o levantamento manual de carga. MOTRIZ, v. 4, n. 2, 1998.

GRANDJEAN, E. Manual de Ergonomia. 4. ed. Porto Alegre: Bockman, 1998. p. 87-93-151.

GRIECO, A. et al. Epidemiology of musculoskeletal Disorders duo to Biomechanical Overload. Ergonomics, Taylor \& Francis, v. 41, n. 9, p.1253-1260, 1998.

GUZMÁN, W. S.; POUTOU, E. L. C.; CRUZ, H. V. Trastornos musculoesqueléticos relacionados con las condiciones de trabajo de estibadores y operadores de equipos montacargas en el puerto de la Habana. Revista Cubana Salud Trabajo, v. 6, n. 1, 2005.

HILDEBRANDT, V. $\mathrm{H}$. et al. Dutch Musculoskeletal Questionnaire: description and basic qualities.Ergonomics, v. 44, n. 12, p. 1042-1044, 2001. PMid:11780727. http:// dx.doi.org/10.1080/00140130110087437

HOOZEMANS, M. J. M. et al. Pushing and pulling in relation to muskuloskeletal disorders: a review of risk factors. Ergonomics, v. 41, n. 6, p. 760-774, 1998. PMid:9629062. http://dx.doi.org/10.1080/001401398186621

INSTITUTO NAVARRO DE SALUD LABORAL. Impacto en salud. Navarra. Disponível em: <http://www.cfnavarra. es/insl/tme/intro2.htm>. Acesso em: 25 jan. 2008.
KERR, M. et al. Biomechanical and Psychosocial Risk Factors for Low Back Pain at Work. American Journal of Public Health, v. 91, n. 7, p. 1069-1075, 2001. PMid:11441733. PMCid:1446725. http://dx.doi. org/10.2105/AJPH.91.7.1069

KUORINKA, B. et al. Standardised Nordic questionnaires for the analysis of musculoskeletal symptoms. Applied Ergonomics, v. 18, n. 3, p. 233-237, 1987.http://dx.doi. org/10.1016/0003-6870(87)90010-X

MALCHAIRE, J. Lesiones de Miembros Superiores por Trauma Cumulativo: Estratégia de Prevención. 2. ed. Bélgica: INRCT, 1998. p. 21-22.

MARRAS, W. S. Occupational low back disorder causation and control. Ergonomics, vol. 43, n. 7, p. 881,2000 . PMid:10929824. http://dx.doi. org/10.1080/001401300409080

MERINO, E. A. D. Efeitos Agudos e Crônicos Causados pelo Manuseio e Movimentação de Cargas no Trabalhador. 1996. Dissertação (Mestrado em Engenharia de Produção)-Universidade Federal de Santa Catarina, Florianópolis.

MIEZEJEWSKI, M; KUMAR, S. Prevalence of low back pain among physicaltherapist in Edmonton, Canadá. Disability Rehabilitation, v. 19, n.8, p. 309-317, 1997.

PINHEIRO, F. A.; TRÓCOLLI, B. T.; CARVALHO, C. V. Validação do Questionário Nórdico de Sintomas Osteomusculares como Medida de Morbidade. Revista da Saúde Pública, v. 36, n. 3, 2002.

VOGT, M. S. L. Prevalência e severidade da dor, cervical elombar, nos servidores técnicos-administrativos da Universidade Federal de Santa Maria-RS. 2000. Dissertação (Mestrado em Engenharia de Produção)-Universidade Federal de Santa Catarina, Florianópolis, 2000.

WATERS, T. National efforts to identify research issues related to prevention of work-related musculoskeletal disorders. Journal of Electromyography and Kinesiology, v. 14, p. 7-12, 2004. PMid:14759745. http://dx.doi. org/10.1016/j.jelekin.2003.09.004

WATKINS, J. Structure and function of the musculoskeletal system. 1999. $331 \mathrm{p}$.

WISNER, A. A inteligência no trabalho: textos selecionados de ergonomia. São Paulo: Fundacentro, 1994.

\section{Prevalence of muscle-skeletal symptoms for load workers}

\section{Abstract}

Handling load is an activity that predisposes the worker to risks due to biomechanical factors, excess of force, inadequate positions and organizational factors. These organizational factors may reflect injuries to workers' health and production when used in an inadequate way. This study was carried out using 3 wholesale businesses, aiming to identify the risk factors that could lead to the prevalence of muscle-skeletal symptoms. An organizational questionnaire, a Nordic questionnaire for musculoskeletal symptoms and a guide for assessment and prevention of risks related to handling load was applied to a select sample of 134 workers. It was possible to notice that the loading, the adopted positions and the pain symptoms (63.4\% of the sample), associated to the previous factors, may represent a health risk. The results supported the studies, establishing strong indications between physical load of work and muscle-skeletal symptoms.

\section{Keywords}

Muscle-skeletal symptoms. Physical charge. Ergonomics. 